\title{
Three Scenarios For Teacher Education
}

Richard Wisniewski

University of Oklahoma

Teacher education in the United States has reached a condition where choices must be made to determine its future. I do not deal with all actors or forces that impinge on those choices. It is also not necessary to recite the familiar litany of criticisms and weaknesses ascribed to schools of education. My focus is on those accountable for the preparation of teachers and the three paths open to us. Despite compelling contrary evidence, my thesis is that it may be possible for teacher educators in selected institutions to help shape a positive future.

There is little in the history of teacher education to suggest that such leadership will be forthcoming. Teacher education has long been characterized by reaction rather than fervor. In that condition it is like any other profession. At the same time, the malais in which teacher education finds itself is becoming more acute. Public cries for reform make it progressively more difficult for teacher educators to hide from criticism.

Each time a segment of the public criticizes school achievement levels, it is also lodging a complaint against those who prepare educational personnel. Despite decades of rationalization and avoidance behavior, there is no honest way of shirking accountability for the quality of public education on the part of teacher educators. The quality of public education and the quality of teacher preparation are irrevocably entwined. Given the need to strengthen public education, indeed to save public education, a growing number of teacher educators recognize that the opportunity to reform education has never been better. However, reform is only one of three possible scenarios.

In describing three possible scenarios, my hope is that some teacher educators will coalesce around the most positive option. The scenarios outlined are realistic. They already partially exist, and their antecedents are already visible. The first scenario is predicated on a continuation of current practices. This is the bleakest of the choices. It offers no hope for the teaching profession or for improvement in the quality of teacher preparation.

The second scenario derives from events occurring in several states, changes that can influence the future positively. These changes are predicated on ameliorative legislation that will bring about a strengthened profession. The changes may be superficial, but they portend improvements in teacher education.

The third scenario is the most positive for it includes the development of professional schools of education and extended periods of preparation. For this to occur, major reforms are needed.

There is a fourth scenario that must be noted. One hears

Wisniewski is Dean of Education at the University of Oklahoma, Norman, Oklahoma.

\author{
The scenarios outlined are realistic. They \\ already partially exist, and their antece- \\ dents are already visible.
}

comments that schools of education will be phased out of existence in the next decade. A wave of national hysteria would need to develop for wholesale closings to be demanded. There is no evidence of such a hysteria. Fiscal problems and legislative intervention in some states will force some closings. The long legacy of concerns over the quality of teacher preparation will fuel the debate leading to some closings. No institution disappears totally save over a long historical period. Given the importance of schools to our society, the elimination of colleges preparing educational personnel on other than a selected basis is not a likely scenario, as attention-getting as such rhetoric may be.

These scenarios can only be outlined here. Convention debates and legislation in some states suggest that these choices are being debated. Movement along all three paths is in progress.

\section{The Most Likely Scenario}

Looking 10 years into the future is not difficult. As McCluhan stated, we look into the future through rear-view mirrors. His phrase suggests that the future is essentially a continuation of trend lines already in place. If we make the assumption that teacher education will remain a campusbased baccalaureate process, we can predict with some certainty the continuation of the foliowing trends.

Confidence in public schools will continue to diminish because of concerns regarding student achievement. Confidence in teachers will also continue to diminish. Because schools of education prepare those teachers, confidence in the abilities of teacher educators will further decline. Each downward step in confidence feeds on and accelerates the others. In this spiral, it is clear that public schools will eventually serve only the poor. More affluent families, those seeking higher status or better opportunities for their children, will support a variety of private and denominational schools.

Enrollments in colleges of education are not likely to increase, particularly at the undergraduate level. There may be an enrollment spurt as teacher shortages occur due to a blip in the birth rate or because of conditions in selected states. It is conceivable that shortages of "gifted" teachers will occur should that movement gain in support. Fellowship programs to recruit mathematics and science teachers will emerge.

Newsweek and Time will, with regularity, provide negative assessments of the public schools and teacher education. They will accurately report that public education is in serious trouble and that schools of education continue to be the stepchildren of the academy. Studies such as the recent Coleman examination of public and private education will proliferate. They will have the effect of further 
weakening confidence in the schools, however inadequate the study.

In the work-a-day world of teacher educators, most schools of education will continue to be of low status in the academic Pantheon. The graying of a heavily tenured faculty will continue. The schism between education and other campus units will grow wider. Turf fights over credit and student numbers will drain faculty energies.

In short, a continuation of the four-year preparation pattern will lead to a further deterioration in the quality of public education and the grinding down of teacher education as a viable profession. These trend lines are negative, thus the future is negative. It is possible that 10 years from now teacher educators will look back on the early 80 s as "the good old days."

This assessment is not totally pessimistic. We are all aware of pleas for improvement and the selected programs that show the vitality of teacher education. This scenario does not denigrate the efforts of thousands of first-rate teacher educators who battle against the odds. It is a realistic scenario, however. Societal attitudes regarding teacher preparation lean toward the negative and they contribute to this depressing scenario. Societal attitudes and expectations significantly determine who becomes a teacher, or a teacher educator for that matter. They determine how persons will be prepared, the resources available, salary scales, and what a teacher is expected to do. No amount of onward and upward exhortation nor of Pollyannish hopes alter the hard realities of the status of teacher education in this era. We are in trouble and have been for some time.

\section{A More Positive Scenario}

Teacher education, like all of education, is a state responsibility. That fact offers some hope. Federal aid has supported a multitude of needed services that states have either ignored or could not afford to implement. Regretfully, that aid is being dismantled. The block grant concept at least reflects the legal premise that the ultimate responsibility for education is at the state level. It is possible that on a state-by-state basis improvements in teacher education can and will take place.

Oklahoma is one of the states that has enacted legislation that portends a more positive future for the teaching profession. Bill 1706 addresses a number of the major components in the teacher education process. The legislation requires higher admission standards to be implemented for all teacher education programs in Oklahoma. It requires more clinical/field work to be included in that preparation. It requires future teachers to pass state-controlled examinations in their subject area(s) prior to graduation. The bill takes from colleges of education the power to recommend certification for graduates. Instead, schools of education can only recommend persons for a one year license to teach.

The bill requires that all future teachers will serve as entry-year teachers or interns. The entry-year teacher is a fulltime teacher at full pay for one year. During that year, the intern is mentored by a three-person committee made up of a consulting teacher, a school principal and a professor of higher education. This three-person committee not only serves as a mentor, it will also make the decision as to whe- ther the person should be certified. In effect, Bill 1706 extends the preparation process to five years.

The bill includes continuing education provisions for teachers and professors of education. Professors of education, including deans, are required to provide evidence each five years that they are maintaining positive working relationships with the profession. The suggestion is made that professors return to the classroom for a 10 day period during each five years as one way of demonstrating that involvement. All these provisions became operational in 1982.

In the context of teacher education measures emerging in other states, 1706 is non-punitive. It requires all the above accomplishments but leaves to the profession, i.e., colleges of education, teacher associations, school boards, the State Department of Education, and the Professional Standards Board, the responsibility for achieving these goals. The bill is positive for it trusts the profession to improve itself. It has sufficient teeth to force a working-together on these goals. Throughout the process leading to the bill, legislative leaders made clear they did not wish to dictate curriculum. Their goal was to provide a framework within which professionals could address the improvement of their work.

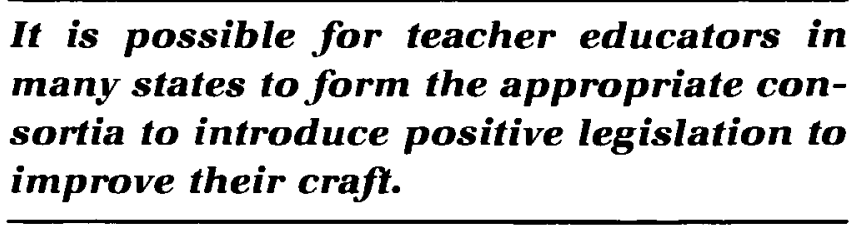

Other states are considering similar forms of legislation. It is possible for teacher educators in many states to form the appropriate consortia to introduce positive legislation to improve their craft. There is, of course, debate as to whether a legislative approach is desirable. Given the fragmented nature of teacher education and of teaching, it has been amply demonstrated that a unified professional leadership is unlikely other than when legislative mandates are threatened. Legislative mandates can be either positive or negative. In either case, legislatures will essentially reflect public attitudes toward teaching and teacher educators.

If teacher educators take the initiative in designing mandates that deal openly with criticisms leveled at teacher education, those mandates are likely to have public support. Where teacher educators resist dealing with criticisms, legislative mandates are likely to be punitive and coercive. The choice for teacher educators, in the rhetoric of the $60 \mathrm{~s}$, is to be part of the problem or the solution.

In states where teacher educators become active participants in the improvement of teacher preparation and the building of a true profession, they have a positive future. They can make a contribution to the improvement of public education and the status of teacher education.

\section{The Most Positive Scenario}

The most positive scenario is the most difficult to achieve. The development of professional schools of education and extended periods of teacher preparation form the heart of this scenario. Linking the characteristics of a professional school to extended periods of preparation is vital to understanding this goal. Even if schools of education achieve some of the attributes of true professional schools, there is 
no guarantee they will provide better prepared teachers unless they also move into extended periods of preparation. Reforms predicated on current four-year frameworks are unlikely to achieve important results. Increasing the time factor is meaningless, of course, unless the rigor of selection and preparation are also dramatically increased. Both changes are needed simultaneously.

\section{Even if schools of education achieve some of the attributes of true pro- fessional schools, there is no guar- antee they will provide better pre- pared teachers unless they also move into extended periods of pre- paration.}

Noting some characteristics of a professional school will underscore the depth of change needed. These characteristics include a limited enrollment. A firm decision has to be made as to how many students can be prepared excellently for the profession. The ballooning of classes because of market conditions or FTE concerns has led to the compromises in quality that haunt teacher preparation. In a mature profession, persons admitted are carefully screened. In that process, affirmative action goals must be applied for teaching must reflect the strength of a multi-cultural society. Indeed, there is some reason to believe that limiting enroliments is more likely to achieve affirmative action goals than the open-door policy now in effect. Teaching must become competitive for talent, and that goal includes seeking candidates rather than waiting to see who knocks. An exposition of this argument would require more space than possible here.

Students would be admitted on a once-a-year basis so that there would be a class of ' 85 , ' 86 , and so on. Experience supports the conclusion that persons moving through a program as a group provide peer support for one another. Morale factors can evolve that are not likely in the factory system of teacher preparation characteristic of many large institutions. Despite the badgering given small institutions in our profession, it should be noted that some private schools are small enough to achieve a sense of purpose far better than large, unarticulated programs. While no more a professional school than a major land-grant institution, small colleges at least have small numbers of members as a positive attribute.

The program in a true professional school would be clinically-based and the theory-practice gap would be systematically attacked. State-of-the-art scholarship would form the theory base for instruction. Many practices now common in schools of education related to courses and field work would be dramatically revised or rejected. Teacher educators in experimental and pilot programs have demonstrated repeatedly that the most effective way to deal with the theo$\mathrm{ry} / \mathrm{practice}$ gap is for professors to work intensively with students and classroom teachers during the total preparation process. Loosely articulated courses cannot bridge the gap. Decades of evidence support this conclusion.
All subject matter requirements would be completed prior to admission to the professional school of education. The School of Pedogogy, to use B.O. Smith's term, would not accept persons unless they had completed full bachelor degrees in appropriate subject areas. Pedogogy would be the focus of the professional school and there would be no attempt at "making-up" academic competencies. Admission to the school would be determined by demonstrated academic competence, an aptitude for teaching, and space in the clinical practices portions of the curriculum. Persons without requisite qualities should not be teachers, and the virtual open-door policy that now characterizes preparation programs would be replaced by careful screening.

Ideally, courses as we know them would be obsolete in a true professional school. In their place, competencies blending theory and clinical practices requisite to teaching would be practiced daily on and off campus by professors and their students. The students would work with their professors in school and agency settings regularly. Professors would serve as mentors as well as demonstrators and evaluators. $A$ professor of education would make regular rounds, visiting selected schools and projects each week. The analogy here is to a physician making rounds in hospitals and demonstrating skills to interns. "Farming students out" for student teaching would no longer be an acceptable practice. Training sites would be rigorously selected. Teachers and administrators in such sites would be integral to all policy-making regarding clinical experiences.

Such intensive activity cannot be done on a part-time basis. One reason that teaching is a semi-profession and has no likelihood of moving from that status is because teacher preparation is a part-time activity. Rarely is it an intensive full-time experience. A professional school would require one to two years of such intensive involvement. The changes needed in professorial traditions, such as load and reward systems, are profound. Equally profound would be changes needed in the role of teachers once inducted into the profession. The latter changes would require discussion beyond the scope of this paper.

One reason that teaching is a semi-profession and has no likelihood of moving from that status is because teacher preparation is a part-time activity.

All the activities noted must be accomplished in concer with the profession. Practicing teachers must be deeply in volved in the preparation of future teachers, and teache associations must be intimately involved in helping to se policies for professional schools. The profession must have a voice in the admission and exit requirements of eacr professional school. Anything less perpetuates the gulf tha: now separates most practitioners from professors.

These are but some characteristics of a first-rate profes. sional school. Questions related to how such a professiona school fits on a college campus need separate analysis. It is possible that professional schools of education will have tc be developed as institutes somewhat separate from univer. sity campuses, much as is the case with medical and lan schools. Professional schools can be part of a university structure, but their budgeting and missions must be dis. crete. 
For those teacher educators who have spent a lifetime in compromise, seeking to improve programs with limited budgets and facilities, the thought of discrete institutes of preparation may be threatening. The point here is not to argue the pros and cons of university status, which I personally support. The goal here is only to suggest that the most positive scenario calls for major shifts in thinking about the structure of teacher education. These thoughts outline some options and issues related to the goal of creating professional level schools. Whatever their form, we must have profes- sional schools with sufficient autonomy to do their jobs properly. The compromises that now riddle teacher education must become historical artifacts rather than part of the dayto-day grind of our professional lives.

An extended period of preparation is absolutely essential if we are to have the time to prepare teaschers well. Little more needs to be said about the matter for Robert Howsam, George Denemark and others have made the case for "lifespace" in the preparation process. I am in their debt as must

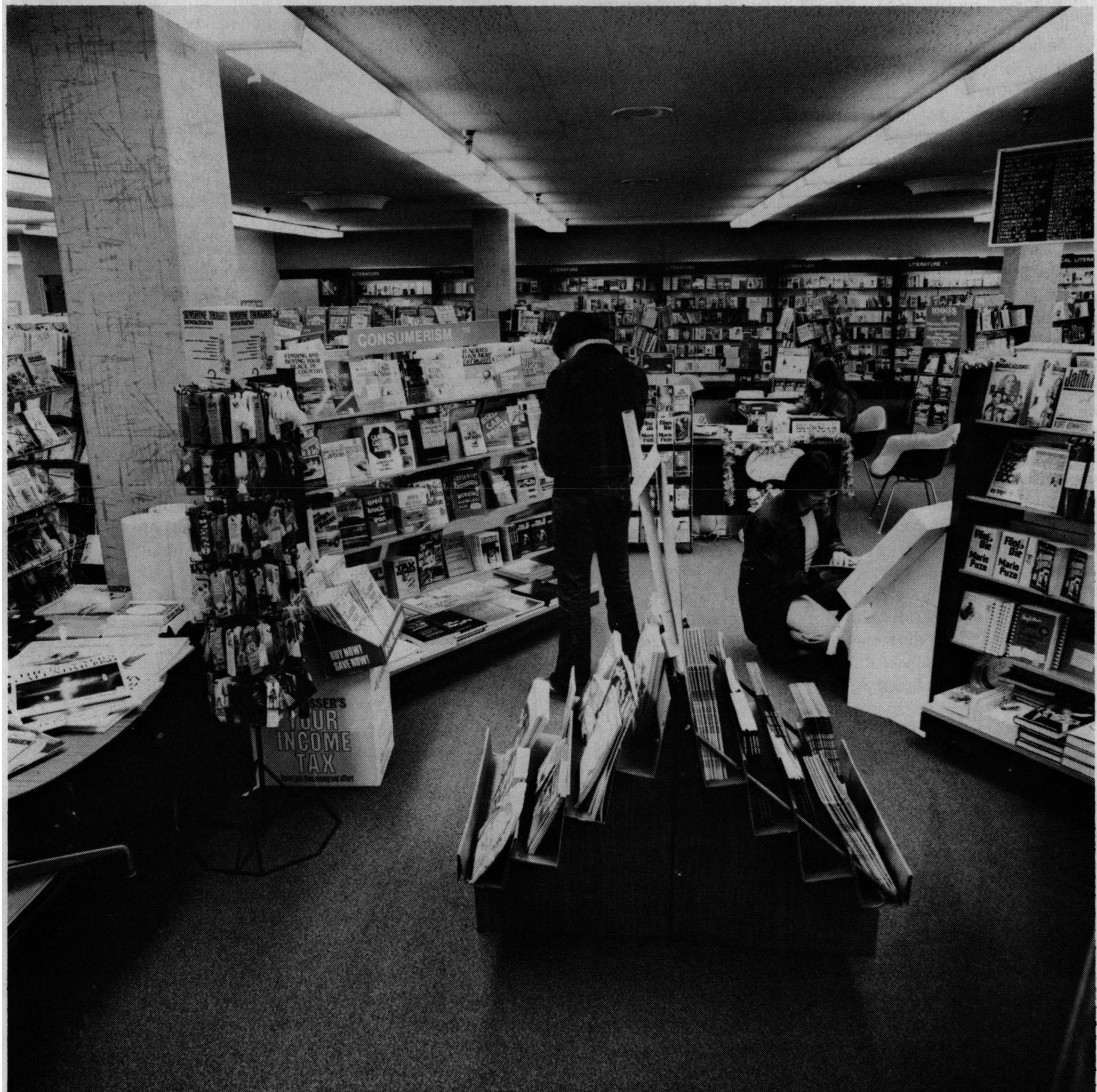

Photograph by George Tarbay, Art/Photo Office, Northern Illinois University. 
be obvious from these remarks. While calls for reforms vary in emphasis, I have emphasized that a professional school requires intensive fulltime involvement. Among its other characteristics, liberal arts preparation must be fully completed before admission, i.e., teacher preparation must become a post-baccalaureate process. A rigorous clinical preparation is needed. The internship as the mechanism for entering the profession must replace the sink-or-swim mode we continue to endure. The masters degree would, of course, be the credential for entering teaching.

These goals cannot be achieved within any four-year program. That fact has been demonstrated so sharply over the past decade that debating the issue hardly seems worthwhile. If we are serious about teaching becoming an honored calling, the admission process, the rigor of preparation, and the length of preparation must all be increased. Not everyone can be or should be a teacher. Teachers ought to be as well prepared at the point of entry as lawyers, dentists, nurses or physicians. Our "yes-but" responses to this goal merely reflect how conditioned we have become to compromise and low-status among other professions.

Should professional schools emerge over the next two decades, we will look back on the four-year preparation process as one appropriate for paraprofessionals. In truth, the level of preparation now earned by teachers is at the paraprofessional level. It does not have to remain so, and it is possible that in selected institutions - and on a state basis - extended periods of preparation in first-rate professional schools will occur. The impact of these developments on the quality of public schooling, on the achievement levels of students, and on societal expectations and rewards for teachers will be far reaching and positive.

Teaching can become a highly honored profession in our society. We have the resources; we have the need. We do not have the sense of unity needed from the persons responsible for the preparation of teachers. We have leaders among us, but we have yet to achieve the power of a unified teacher education profession. We are too fragmented to be anything but impotent in the face of adversity or opportunity. Those teacher educators in selected states who have coalesced around goals similar to those suggested here are contributing to a positive future for public education. At this juncture, their ranks are thin.

\section{Conclusions}

Reviewing the options, option one, i.e., "doing more of the same but working harder," is a depressing choice. Many teacher educators have made the decision to "ride-out" criticism and discontent until their retirement. In my judgment, this scenario must be resisted.

Options two and three are both far more positive. Option two provides a mechanism by which educators, teachers, associations, and others can work on legislative mandates for improving the profession in selected states. Such mandates may not dramatically improve teacher preparation, but they will answer some criticisms and move the profession in the right direction. Option two is an honorable and positive way of moving forward and contributing to the improvement and preservation of public education.

Option three is the most difficult to achieve. It means reversing the traditions of 100 years. It means seriously altering the status of schools of education and on campuses and in society. It means initiating a major political process in which the outcomes cannot be sure or immediate. Nonetheless, it is a realistic goal. It builds on option two and goes the extra mile. It means going for broke.

Teacher educators supporting the second and third scenarios are making positive contributions to public education, to their students and their calling. Those who determine to weather the waves of criticism will, as in any profession, find ways of resisting colleagues who press for reform. What is intriguing in this dynamic is that the enemy is indeed us, now a trite homily. There are many helping hands in public life, outside the profession, who support the reform of teacher education. That segment of the public will respond if teacher educators forthrightly address the criticisms leveled at them and accept some responsibility for public school outcomes. It is the insularity of many teacher educators that has brought us to our current state.

We can create a new future for teacher education and public education. Our fragmentation must be confronted and overcome. If we continue to limit and define our world to the courses we control, we will never address the critical questions of competence and quality. We must end our divorce from the profession. Professional associations want to represent a first-rate profession. They cannot understand why so many professors of education are reluctant to join them in the struggle to achieve that goal.

To argue that the improvement of teacher education is the right thing to do is meaningless. If it were the right thing to do, rhetoric would not be needed. Rather, we must recognize the scenarios outlined. The latter two call for energies and dedications that cannot be faked. The decisions that need to be made are laced with professional risk. The issues that must be raised will upset and confuse many in the profession. The reversal of many traditions is not easy. These are hardly issues resolved over cocktails or at conferences.

There is hope, however. If we review the development of teacher education, it is clear that the flow of history is with us. it is less than 100 years ago that the high school graduate became an elementary teacher virtually automatically. It was only 75 years ago that the two-year normal school was the norm for entering the profession. it has only been 40 or so years since the baccalaureate pattern took hold. We have made remarkable progress as a profession in addressing the quality of our calling. The times are right for the next steps to be taken.

We do not need to look for a Flexner to goad the process. Our Flexner reports have already been published. Educating a Profession and the more recent Designing a School of Pedogogy outline the condition of teacher education and prospects for a vastly improved profession. We already have leaders on the scene: B.O. Smith, Robert Howsam, Dean Corrigan, George Denemark, and others have been advocating these and similar ideas for years. We need to rally about these and other leaders.

The future for teacher education is embedded in some variant of the three options outlined. There is hope and there are opportunities for those who have not given up on their profession. Like all major decisions, each of us must live with the consequences of our actions - as well as of our failures to act.

Some who have chosen ideas suggested in scenarios two and three can occasionally be heard muttering, "Why me, Why me?" One can only suggest there is hope for people who ask that question. They probably know the answer. $\checkmark$ 